\title{
Intraseptal infusions of 8-OH-DPAT in the rat impairs water-maze performances: effects on memory or anxiety?
}

\author{
Fabrice Bertrand, Olivia Lehmann, Christine Lazarus, \\ Hélène Jeltsch, Jean-Christophe Cassel ${ }^{*}$
}

Laboratoire de Neurosciences Comportementales et Cognitives, LN2C, UMR 7521 du CNRS/Université Louis Pasteur, 12 rue Goethe, F-67000 Strasbourg, France

Received 7 September 1999; received in revised form 22 November 1999; accepted 25 November 1999

\begin{abstract}
In the rat, 5- $\mathrm{HT}_{1 \mathrm{~A}}$ receptors are found on medial septal cholinergic neurons. The effects of intraseptal infusions of the 5$\mathrm{HT}_{1 \mathrm{~A}}$ receptor agonist 8-OH-DPAT (8-hydroxy-2-(di-n-propyl-amino)-tertralin) were assessed on reference memory performances in a water maze. Compared with vehicle infusions, 0.5 and $4 \mu \mathrm{g}$ of 8-OH-DPAT significantly impaired (but did not prevent) acquisition of the task and probe-trial performances. The results suggest that activation of 5- $\mathrm{TH}_{1 \mathrm{~A}}$ receptors in the (medial) septal area impairs spatial learning, perhaps directly by reducing the hippocampal cholinergic tonus, or indirectly by an effect on anxiety. (C) 2000 Elsevier Science Ireland Ltd. All rights reserved.
\end{abstract}

Keywords: Rat; Water maze; Spatial reference memory; Anxiety; $5-\mathrm{HT}_{1 \mathrm{~A}}$ receptor; Medial septum

Serotonin may modulate cholinergic function in different regions of the brain and interactions between both neurotransmission systems may be important for learning and memory (e.g. [3]). The medial septum (MS) area, which provides the hippocampus with cholinergic fibers and is critical for memory [20], is a potential support for such interactions. In the rat, it receives serotonergic fibers from the raphe nuclei [1]. Moreover, serotonin-containing terminals synapse on septohippocampal neurons [15]. Serotonin may act on MS neurons by activating $5-\mathrm{HT}_{1 \mathrm{~A}}$ receptors which are in high density in this structure [18]. A part of these receptors may be located postsynaptically $[4,10,18]$, and a subpopulation of cholinergic neurons in the MS express $5-\mathrm{HT}_{1 \mathrm{~A}}$ receptors [9]. Little is known about the role of these receptors in behavior and memory. Intraseptal injections of the specific 5- $\mathrm{HT}_{1 \mathrm{~A}}$ agonist 8-OH-DPAT (8hydroxy-2-(di-n-propyl-amino)-tertralin) increase maternal aggressive behavior [5] and influence anxiety [6,13,14]. When infused into the lateral septum (LS), 8-OH-DPAT impairs retention of passive avoidance [11]. However, nothing is known about the involvement of septal 5- $\mathrm{HT}_{1 \mathrm{~A}}$ receptors in spatial learning. Using a reference memory task in

* Corresponding author. Tel.: +33-3-88-358-435; fax: +33-388-358-442.

E-mail address: jean-christophe.cassel@psycho-ulp. u-strasbg.fr (J.-C. Cassel) the water maze, we investigated whether intraseptal infusions of 8-OH-DPAT could alter spatial learning.

All procedures involving animals were conducted according to international laws and policies. The study used 40 three-month old Long-Evans male rats (CERJ, France), housed individually in transparent cages (room temperature $21^{\circ} \mathrm{C}$, lights on from 07:00 to 19:00 h). Microinjector guide canula were implanted in all rats, 6-7 days before testing, under equithesin anesthesia ( $3.5 \mathrm{ml} / \mathrm{kg}$, i.p.). The stereotaxic coordinates were (in $\mathrm{mm}$ ) $\mathrm{A}=+0.8, \mathrm{~L}=+1.1$ and $\mathrm{V}=$ -5.3 from Bregma [17], with a mediolateral angle of $10^{\circ}$ and the incisor bar at $3 \mathrm{~mm}$ underneath the interaural line. As the microinjector needle was $1 \mathrm{~mm}$ longer than the guide canula, the tip of the latter was placed $1 \mathrm{~mm}$ above the injection site.

Spatial learning was assessed in a water maze using a protocol placing emphasis on reference memory [8]. The platform $(\varnothing 11 \mathrm{~cm})$, lowered $1 \mathrm{~cm}$ underneath water opacified with powdered milk, remained at the same place for all acquisition trials. During five days, the rats underwent four consecutive trials/day, starting each time from a different position at the edge of the pool $(\varnothing 160 \mathrm{~cm})$. Each of the 19 acquisition trials was limited to $60 \mathrm{~s}$, after which the rats that did not find the platform were placed on it by the experimenter. Escape latencies and distances swum from the starting point to the platform were collected. For the probe trial 
(trial 20), the platform was removed from the pool. During $60 \mathrm{~s}$, the distance swum and time spent by the rat in each quadrant were recorded.

The rats were allocated to one of four groups: CSF, DPAT0.5, DPAT4 and SHAM. CSF rats $(n=9)$ were microinjected into the MS with artificial cerebrospinal fluid (aCSF: Na 150, K 3.0, Ca 1.4, Mg 0.8, P 1.0, Cl 155, in $\mathrm{mM})$, DPAT0.5 rats $(n=11)$ with $0.5 \mu \mathrm{g}$ and DPAT4 rats $(n=11)$ with $4.0 \mu \mathrm{g}$ of 8-OH-DPAT (Sigma-Aldrich, USA) in aCSF. The microinjections $(0.5 \mu \mathrm{l}$ in $1 \mathrm{~min})$ were performed $10 \mathrm{~min}$ before testing. The nine remaining rats (SHAM) were handled as the others, but did not receive injections. The rats were tested according to a random order repeated on each day.

At the end of testing, the rats were sacrificed, their brain fixed with a $4 \%$ paraformaldehyde solution perfused transcardially and cut into $30-\mu \mathrm{m}$ thick coronal sections. Sections were stained with cresyl violet, or for acetylcholinesterase (AChE) using acetylthiocholine iodide $(4 \mathrm{mM})$ as the substrate and ethopropazine $(0.3 \mathrm{mM})$ to inhibit nonspecific cholinesterases.

For the acquisition trials, daily mean escape latencies, distances and velocities were compared by a two-way analysis of variance (ANOVA) for repeated measures (Group $\times$ Day). For the probe trial, time spent and distances swum in each quadrant, and mean velocities during the trial were compared by one-way ANOVAs. Two-by-two comparisons used the Newman-Keuls test. Rats with inappropriate implantation of the guide canula were discarded from analysis (CSF, $n=2$; DPAT0.5, $n=1$ ).

Appropriate injection sites are shown in Fig. 1A-D. No important histological change was observed within the MS region, except a slight gliosis restricted to the injection site and the canula track overlying the MS (Fig. 1E,F). AChEstaining did not show any noticeable difference among the groups within the MS or within the hippocampal formation (data not illustrated).

Comparison of acquisition and probe-trial performances, as well as the velocities, in SHAM and CSF rats showed no significant difference $\left(F_{1,14}<2.3, P>0.15\right.$ in all cases). From day 1 to 5 , mean values \pm SEM of SHAM rats were: distances $(\mathrm{cm}): 1080 \pm 102,643 \pm 89,600 \pm 71,482 \pm 96$, $330 \pm 48$; escape latencies (s): $50.5 \pm 3.4,24.8 \pm 3.7,23.5 \pm$ $3.2,17.7 \pm 3.2,13.6 \pm 1.7$. During the probe trial, we found $629 \pm 29 \mathrm{~cm}$ swum and $27 \pm 2.0 \mathrm{~s}$ spent in the probe quadrant (where the platform was during the acquisition trials). Further analyses considered performances of CSF, DPAT0.5 and DPAT4 rats. The velocities did not differ significantly among the three groups, whether during the acquisition trials or the probe trial, which did not differ from each other (CSF, $26.2 \pm 0.8$; DPAT0.5, $26.9 \pm 0.5$; DPAT4, $26.6 \pm 0.5 \mathrm{~cm} / \mathrm{s}$ ). During the acquisition trials, there was a significant decrease in distances $\left(F_{4,100}=43.5, P<0.0001\right)$ and escape latencies $\left(F_{4,100}=83.3, P<0.0001\right)$ over the days (Fig. 2). The Group $\times$ Day interaction was not significant $\left(F_{8,100}<1.44\right.$ in each case). There was also a significant Group effect on
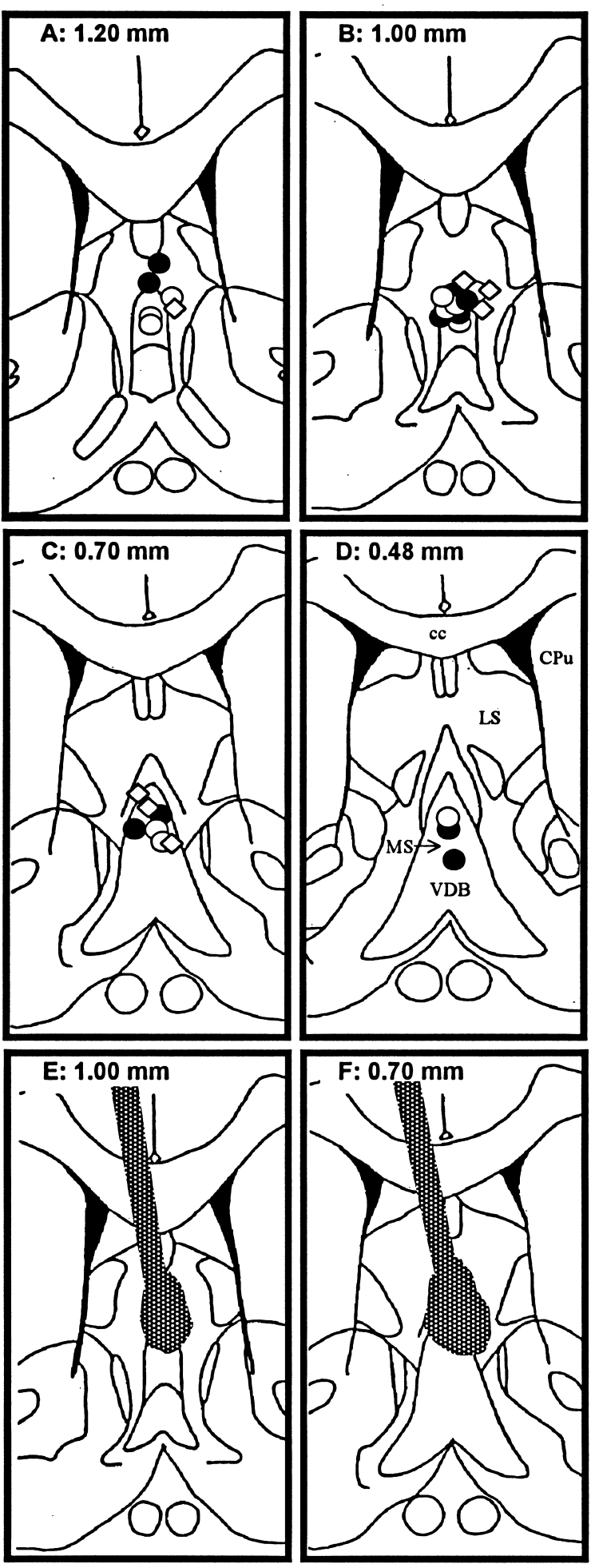

Fig. 1. (A-D) Schematic representation of appropriate injection sites on coronal sections through the medial septum; coordinates in $\mathrm{mm}$ from Bregma [17]. Open diamonds, CSF group $(n=7)$; closed circles, DPAT0.5 group $(n=10)$; open circles, DPAT4 group ( $n=11)$. MS, medial septum; VDB, vertical limb of diagonal band of Broca; LS, lateral septum; cc, corpus callosum; $\mathrm{CPu}$, caudate putamen. (E,F) Largest damage due to the canula and injections at anteriorities where most injection sites were located (shaded area). 

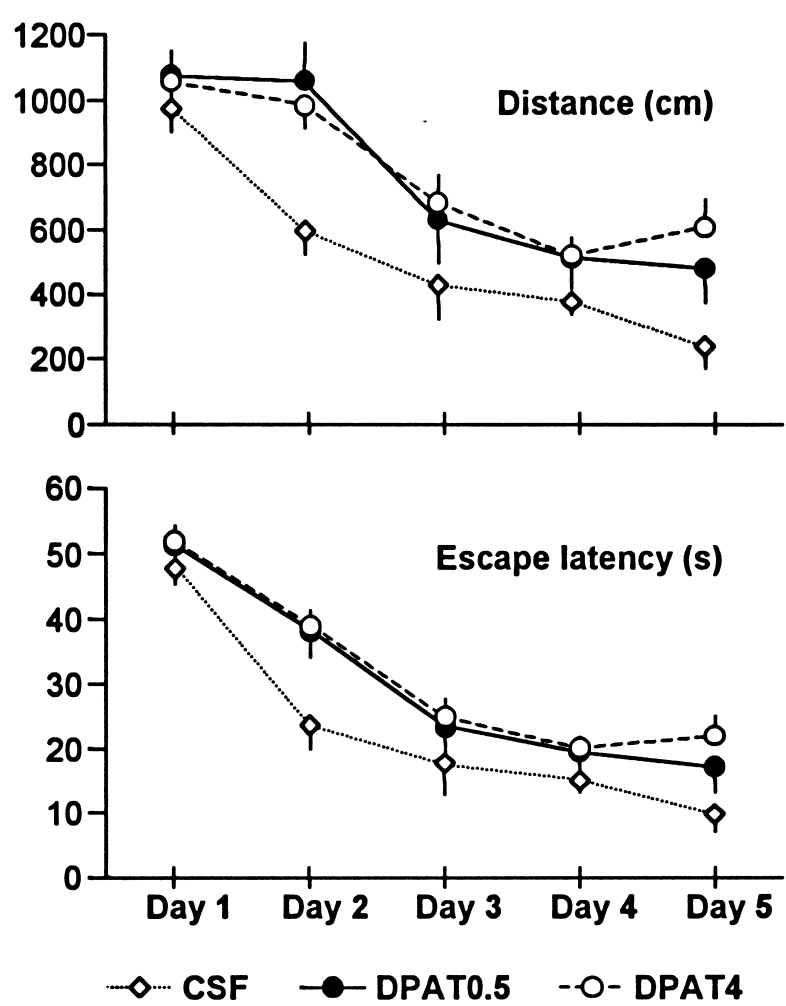

Fig. 2. Acquisition trials. Daily mean \pm SEM distances and escape latencies found in $\operatorname{CSF}(n=7)$, DPAT0.5 $(n=10)$ and DPAT4 $(n=11)$ rats.

distances $\left(F_{2,25}=3.96, P<0.05\right)$ : distances in DPAT0.5 and DPAT4 groups did not differ from each other, but were higher than in the CSF group $(P<0.05$; Fig. 2$)$. A marginal effect was found on escape latencies $\left(F_{2,25}=3.23\right.$, $P=0.057$; Fig. 2).

During the probe trial (Table 1), a global Group effect was found on distances swum $\left(F_{2,25}=7.59, P<0.01\right)$ and time spent $\left(F_{2,25}=11.01, P<0.001\right)$ in the probe quadrant, but also in the opposite quadrant $\left(F_{2,25}=4.74\right.$ and 7.69 , respectively, $P<0.05$ ). All statistics are shown in
Table 1. When compared to CSF rats, both DPAT0.5 and DPAT4 rats spent significantly less time $(P<0.01)$ and swum a shorter distance $(P<0.05)$ in the probe quadrant. Conversely, they spent more time $(P<0.01)$ and swam longer distances $(P<0.05)$ in the opposite quadrant. In each quadrant, performances of DPAT0.5 and DPAT4 rats did not differ significantly from each other.

Our results show that intraseptal microinjections of 8OH-DPAT impair, but do not prevent, spatial learning in a water-maze task. During the probe trial, rats infused with 8OH-DPAT did not search for the platform as accurately as the controls. These effects being not different between doses, they seem close to maximal already at the lowest dose. Furthermore, as 8-OH-DPAT had no effect on the rats' velocity, it seems that the drug-induced impairment did not reflect sensorimotor perturbations. This interpretation is strengthened by the fact that the effects were most pronounced on distances, a variable considered poorly sensitive towards sensorimotor biases [12]. Nevertheless, this interpretation requires further support, for instance by testing rats with a visible platform.

Regarding the location of the injection sites, the effects observed could be due to diffusion of 8-OH-DPAT towards structures close to the MS, such as the LS which seems also implicated in spatial memory [7] and where 5- $\mathrm{HT}_{1 \mathrm{~A}}$ receptors have been identified [18]. To our knowledge, there are very few data concerning mnesic effects of 8-OH-DPAT injections into the LS. Lee et al. [11] showed that such injections impaired retention of passive avoidance. Alternatively, 8-OH-DPAT may have reached the hippocampus through the ventricles. When infused directly into the hippocampus, 8-OH-DPAT induces spatial memory impairments [2]. Nevertheless, the deficits that we observed may not be due to activation of hippocampal 5- $\mathrm{HT}_{1 \mathrm{~A}}$ receptors. Intrahippocampal infusions of 2 or $5 \mu \mathrm{g}$ 8-OH-DPAT are required to impair spatial discrimination in a water-maze task, whereas $0.4 \mu \mathrm{g}$ is ineffective [2]. In our experiment, an intraseptal dose of $0.5 \mu \mathrm{g}$ induced clear-cut learning deficits, but was certainly insufficient to allow a significant

Table 1

Probe trial ${ }^{\mathrm{a}}$

\begin{tabular}{lllll}
\hline Group & Probe quadrant & Quadrant 1 & Quadrant 2 & Quadrant 4 \\
\hline & Distance $(\mathrm{cm})$ & & & \\
\cline { 2 - 5 } CSF $(n=7)$ & $747 \pm 56$ & $215 \pm 25$ & $407 \pm 43$ & $280 \pm 48$ \\
DPAT0.5 $(n=10)$ & $621 \pm 41^{*}$ & $336 \pm 32^{*}$ & $415 \pm 27$ & $320 \pm 25$ \\
DPAT4 $(n=11)$ & $522 \pm 52^{*}$ & $353 \pm 38^{*}$ & $389 \pm 29$ & $359 \pm 21$ \\
\cline { 2 - 5 } & Time $(\mathrm{s})$ & & & $9.8 \pm 1.7$ \\
CSF $(n=7)$ & $28.5 \pm 1.6$ & $7.5 \pm 0.9$ & $14.3 \pm 1.7$ & $11.0 \pm 0.9$ \\
DPAT0.5 $(n=10)$ & $22.3 \pm 1.6^{* *}$ & $11.6 \pm 1.0^{* *}$ & $15.0 \pm 0.9$ & $13.1 \pm 0.7^{*}$ \\
DPAT4 $(n=11)$ & $19.4 \pm 1.6^{* *}$ & $13.2 \pm 1.4^{* *}$ & $14.2 \pm 1.0$ & \\
\hline
\end{tabular}

\footnotetext{
${ }^{\text {a }}$ Mean \pm SEM distance swum and time spent in each quadrant of the pool in CSF, DPAT0.5 and DPAT4 rats. Quadrant 1 is opposite to the probe quadrant. ${ }^{*} P<0.05$ and ${ }^{*} P<0.01$ vs. CSF.
} 
amount of 8-OH-DPAT to reach the hippocampus. Moreover, in a three panel-runway task, intrahippocampal infusion of $10 \mu \mathrm{g}$ of 8-OH-DPAT impaired working but not reference memory [16]; in the present experiment, reference memory was clearly impaired. Finally, in a recent experiment performed in our laboratory with testing conditions identical to ours (Lazaris et al., unpublished observations), spatial learning was not prevented by the infusion of $2.5 \mu \mathrm{g}$ of 8-OH-DPAT into each dorsal hippocampus.

Intraseptal infusions of 8-OH-DPAT also influence anxiety $[6,13,14]$. As the Morris water-maze task is based on aversive motivations, it cannot be ruled out that our rats were influenced by effects of 8-OH-DPAT on anxiety. However, as 8-OH-DPAT was described to have anxiogenic or anxiolytic properties, depending on the dose, the gender and the test used $[6,13]$, such a possibility requires further investigations, particularly because anxiety can interfere with the efficiency of spatial memory in rodents [14].

Based on immunohistochemical data and the involvement of hippocampal cholinergic function in spatial cognition, another speculation might consider the regulation of hippocampal acetylcholine (ACh) release through $5-\mathrm{HT}_{1 \mathrm{~A}}$ receptors located on cholinergic neurons in the MS which, for some, receive serotonergic inputs $[9,15]$. These receptors are negatively coupled to adenylyl cyclase and inhibit septal neurons activity in vitro [19]. Thus, in the present study, intraseptal injections of 8-OH-DPAT might have reduced the hippocampal cholinergic tonus and induced memory deficits. To further analyze this issue, determination of hippocampal ACh release after intraseptal infusion of 8$\mathrm{OH}-\mathrm{DPAT}$ is required.

The authors thank Mr. O. Bildstein and R. Paul for animal care, and Ms. A. Lazaris and S. Wirth for technical advice. They acknowledge E. Lilly Corporation for providing research fundings and a post-doctoral fellowship to F.B.

[1] Acsady, L., Arabadzisz, D., Katona, I. and Freund, T.F., Topographic distribution of dorsal and median raphe neurons with hippocampal, septal and dual projection. Acta Biol. Hung., 47 (1996) 9-19.

[2] Carli, M., Lazarova, M., Tatarczynska, E. and Samanin, R., Stimulation of 5-HT1A receptors in the dorsal hippocampus impairs acquisition and performance of a spatial task in a water maze. Brain Res., 595 (1992) 50-56.

[3] Cassel, J.-C. and Jeltsch, H., Serotonergic modulation of cholinergic function in the central nervous system: cognitive implications. Neuroscience, 69 (1995) 1-41.

[4] Chalmers, D.T. and Watson, S.J., Comparative anatomical distribution of 5-HT1A receptor mRNA and 5-HT1A binding in rat brain - a combined in situ hybridisation/in vitro receptor autoradiographic study. Brain Res., 561 (1991) 51-60.

[5] De Almeida, R.M. and Lucion, A.B., 8-OH-DPAT in the median raphe, dorsal periaqueductal gray and corticomedial amygdala nucleus decreases, but in the medial septal area it can increase maternal aggressive behavior in rats. Psychopharmacology (Berl.), 134 (1997) 392-400.

[6] De Almeida, R.M., Giovenardi, M., Charchat, H. and Lucion, A.B., 8-OH-DPAT in the median raphe nucleus decreases while in the medial septal area it may increase anxiety in female rats. Neurosci. Biobehav. Rev., 23 (1998) 259-264.

[7] Farber, H.T., Chlordiazepoxide improves the performance of septal lesioned but not hippocampal lesioned animals in a Morris maze. Brain Res., 725 (1996) 257-262.

[8] Galani, R., Weiss, I., Cassel, J.-C. and Kelche, C., Spatial memory, habituation, and reactions to spatial and nonspatial changes in rats with selective lesions of the hippocampus, the entorhinal cortex or the subiculum. Behav. Brain Res., 96 (1998) 1-12.

[9] Kia, H.K., Brisorgueil, M.J., Daval, G., Langlois, X., Hamon, $M$. and Verge, D., Serotonin1A receptors are expressed by a subpopulation of cholinergic neurons in the rat medial septum and diagonal band of Broca-a double immunocytochemical study. Neuroscience, 74 (1996) 143-154.

[10] Kia, H.K., Brisorgueil, M.J., Hamon, M., Calas, A. and Verge, D., Ultrastructural localization of 5-hydroxytryptamine1A receptors in the rat brain. J. Neurosci. Res., 46 (1996) 697708.

[11] Lee, E.H., Lin, W.R., Chen, H.Y., Shiu, W.H. and Liang, K.C., Fluoxetine and 8-OH-DPAT in the lateral septum enhances and impairs retention of an inhibitory avoidance response in rats. Physiol. Behav., 51 (1992) 681-688.

[12] Lindner, M.D., Plone, M.A., Cain, C.K., Frydel, B., Francis, J.M., Emerich, D.F. and Sutton, R.L., Dissociable long-term cognitive deficits after frontal versus sensorimotor cortical contusions. J. Neurotrauma, 15 (1998) 199-216.

[13] Menard, J. and Treit, D., The septum and the hippocampus differentially mediate anxiolytic effects of $\mathrm{R}(+)-8-\mathrm{OH}-\mathrm{DPAT}$. Behav. Pharmacol., 9 (1998) 93-101.

[14] Micheau, J. and Van Marrewijk, B., Stimulation of 5-HT1A receptors by systemic or medial septum injection induces anxiogenic-like effects and facilitates acquisition of a spatial discrimination task in mice. Prog. Neuro-Psychopharmacol. Biol. Psychiat., 23 (1999) 1113-1133.

[15] Milner, T.A. and Veznedaroglu, E., Serotonin-containing terminals synapse on septohippocampal neurons in the rat. J. Neurosci. Res., 36 (1993) 26-71.

[16] Ohno, M., Yamamoto, T. and Watanabe, S., Blockade of hippocampal nicotinic receptors impairs working memory but not reference memory in rats. Pharmacol. Biochem. Behav., 45 (1993) 89-93.

[17] Paxinos, G. and Watson, P., The Rat Brain in Stereotaxic Coordinates, Academic Press, Sydney, 1986.

[18] Pazos, A. and Palacios, J.M., Quantitative autoradiographic mapping of serotonin receptors in the rat brain. I. Serotonin-1 receptors. Brain Res., 346 (1985) 20-30.

[19] Van den Hooff, P. and Galvan, M., Actions of 5-hydroxytryptamine and 5-HT1A receptor ligands on rat dorso-lateral septal neurons in vitro. Br. J. Pharmacol., 106 (1992) 893-899.

[20] Von Cramon, D.Y. and Müller, U., The septal region and memory. In F. Cohadon (Ed.), Advances and Technical Standards in Neurosurgery. Vol. 24, Springer-Verlag, Austria, 1998, pp. 3-40. 